\title{
Inference Claims
}

\section{David HitchCock}

Department of Philosophy

McMaster University

Hamilton, ON L8S 4K1

hitchckd@mcmaster.ca
Résumé: Une conclusion d'un argument s'ensuit de ses prémisses si et seulement si une proposition vérifonctionnelle acceptable dont l'antécédant est une conjonction de toutes les prémisses de l'argument et dont le conséquent est la conclusion (a) appuie une proposition contrafactuelle et (b) exclut, soit avec certitude ou soit avec réserve par l'usage d'une expression modale, simultanémment l'acceptabilité des prémisses et la non-acceptabilité de la conclusion, même si elle n'exclut pas l'acceptabilité des prémisses et ne requiert pas l'acceptabilité de la conclusion indépendamment des prémisses. Donc, une prémisse implicite avancée pour rendre un argument formellement valide doit être une telle proposition vérifonctionnelle.

Keywords: argument, associated conditional, consequence, counterfactualsupporting generalization, covering generalization, inference, inference claim, material conditional, truth-preservation, truth-transmission

\section{Introduction}

As individuals and as communities, we increase our knowledge by making inferences from things we already know. Argumentation involves such inferences, and invites its addressees to accept them. The arguer implicitly claims that the conclusion of each constituent argument follows from the reason or reasons from which it is drawn. What is the general form of

(C) David Hitchcock. Informal Logic, Vol. 31, No. 3 (2011), pp. 191-228. 
such inference claims? What does it mean to say that a conclusion follows from a reason or reasons?

\section{Following as logically necessary truth-preservation: two objections}

Introductory logic texts nowadays identify following with necessary truth-preservation: if the reasons are true, then the conclusion must be true. See for example Tarski (2002/1936, pp. 178, 183-184), Salmon (1963, p. 18), Etchemendy (1990, pp. 81-82), Forbes (1994, p. 3), Copi and Cohen (2001, p. 43), Hurley (2006, p. 41), and Jeffrey (2006, p. 1). The textbooks go on to explain this necessity as due to a logical form of the argument: if the conclusion follows, it does so because the argument has a contentless form that cannot have an instance with true reasons and an untrue conclusion. (I use the term 'untrue' rather than the usual 'false' so as to accommodate the possibility of a conclusion that is neither true nor false.)

This conception of following, I maintain, is in one respect too broad and in another respect much too narrow.

\subsection{Too broad}

It is too broad in counting a conclusion as following merely because the conclusion must be true or merely because the reasons cannot be true. On the contrary, I hold, there must be a connection between the reasons and the conclusion. Consider the following medieval example:

(1) You are sitting and you are not sitting; therefore Tom is in the corner.

Intuitively, the conclusion does not follow. The principle ex falso quodlibet (from a falsehood anything follows) is at best dubious. Similarly, consider the following parallel example:

(2) Tom is in the corner; therefore, you are not both sitting and not sitting.

Here too, it seems implausible to hold that the conclusion follows. So the principle ex quolibet verum (from anything a truth follows) is also dubious. Rejection of the principles ex falso quodlibet and ex quolibet verum requires revising standard logic, whether classical or intuitionist. Tennant $(1979,1980,1984)$ has shown one way of doing so, although he modifies the relations of deducibility and entailment rather than the relation of following logically. He treats entailment as the converse of 
deducibility, and then puts restrictions on deducibility that simultaneously restrict the extension of the entailment relation. Thus, in example (1) above, Tennant would say that Tom is in the corner follows logically from the premiss you are sitting and you are not sitting but is not entailed by it, because it is not deducible from it once restrictions are imposed on what can count as a proof.

If (unlike Tennant) we identify being entailed with following logically, then we can capture the force of Tennant's restrictions by requiring for a conclusion to follow logically that the argument has a form that not only cannot have an instance with both true reasons and an untrue conclusion, but also can have an instance with true reasons and can have an instance with an untrue conclusion. We can label the additional requirement a requirement of non-triviality: the ruling out of true reasons and an untrue conclusion must be non-trivial, in the sense that it must not be due merely to the ruling out of true reasons or merely to the ruling out of an untrue conclusion. Following standard usage in logic textbooks, let us call an argument in which the conclusion follows logically in this sense a formally valid argument.

\subsection{Too narrow}

The received conception of following is much too narrow in forbidding the form that rules out true premisses and an untrue conclusion to have any content. The restriction to logical or contentless forms seems to be an unwarranted prejudice. If an argument has a form that rules out true reasons and an untrue conclusion in a non-trivial way, then why not admit that the conclusion follows, even if the form has some content?

Consider the hackneyed argument from Socrates' humanity to his mortality:

\section{(3) Socrates is human, so Socrates is mortal.}

This argument is an instance of many forms. One of them is the form: $x$ is human, so $x$ is mortal. Let us suppose that, as a matter of physiological necessity, every human being will eventually die. Then the form cannot have an instance with a true premiss and an untrue conclusion. But it can certainly have an instance with a true premiss, as in the case of our example, where the name 'Socrates' replaces the variable $x$. And it can have an instance with an untrue conclusion, as when we replace the variable $x$ with the name 'seven': seven is not mortal, because numbers are not living organisms and so are not subject to dying. The conclusion that Socrates is mortal thus seems to follow ne- 
cessarily from the premiss that Socrates is human, even though the necessity in question is physiological rather than formal or even (I would maintain) semantic.

The usual response in the western logical tradition to arguments like that from Socrates' humanity to his mortality is to hold that they have an unexpressed premiss, variously described as 'unstated', 'hidden', 'tacit', 'suppressed' or 'missing'. In the Socrates argument of example (3), an argument analyst would attribute to the argument the unexpressed premiss that every human is mortal. With the addition of this premiss, the argument's conclusion follows purely formally, so the received conception of consequence is vindicated. But of course it is vindicated only because the postulation of an unexpressed premiss presupposes that a conclusion that follows from an argument's premisses must follow purely formally. To use the existence of an unexpressed premiss that every human is mortal as a reason for holding that the conclusion of the Socrates argument follows formally would be to reason in a circle, assuming what is to be proved. Further, it is odd to hold that an argument has a premiss that it does not have. Like the emperor in the fairy tale of Hans Christian Andersen who had no clothes, the Socrates argument does not in fact have as a premiss that every human is mortal. If we look at it carefully, with the eyes of a child uncorrupted by logical indoctrination, we will see that it has just one premiss, that Socrates is human. Further, why would a person omit a premiss of their argument? The usual explanation, going back to Aristotle (Rhetoric I.2.1357a16-21) and repeated for example by Quine (1972, p. 169), is that arguers omit a premiss for economy of expression, when the addressees can supply the premiss for themselves, as a matter of common knowledge. Much human linguistic communication is indeed elliptical, relying on context, both linguistic and extra-linguistic, to provide the addressee with what is required to understand what is said or written. But the difficulty with supposing that arguers routinely suppress a premiss that they conceive their argument as having is that we have no awareness of such a supposedly suppressed premiss, even when we are reasoning things out for ourselves (Hitchcock 1985). Readers can check this phenomenological fact directly by reflecting on inferences they make for themselves, immediately after making them. It will readily be discovered both that the inference is not formally valid and that there is no awareness of having omitted a premiss.

Both the reasoning that people use to draw their own conclusions and the arguments that they make to others to support their claims are typically not formally valid. In two collections of arguments selected by random sampling methods, one from books in a university library and the other from calls to phone-in 
radio and television talk shows, fewer than 10 percent of the arguments were formally valid, or candidates for being formally valid (Hitchcock 2002, 2010a). In the remaining arguments, the conclusion would follow, if at all, in virtue of a form with content that ruled out true premisses and an untrue conclusion in a non-trivial way. The Socrates argument of example (3), though artificial, is typical in that respect of how we humans reason and argue.

\section{First reformulation: following as necessary truth- transmission}

If we adjust the received conception of following as formally grounded necessary truth-preservation so as to accommodate the two objections just mentioned, we get an alternative conception of following as what we might call necessary truthtransmission, where the necessity need not be purely formally grounded. On this alternative conception, a conclusion follows from one or more premisses offered in its support if and only if the argument has a form that non-trivially rules out true premisses and an untrue conclusion: no argument of that form can have true premisses and an untrue conclusion, even though an argument of that form can have true premisses and an argument of that form can have an untrue conclusion. The three conditions in this alternative conception can be expressed as conditions on a covering generalization of the argument: there is a generalization of the argument's associated material conditional (the truthfunctional conditional whose antecedent is the conjunction of the argument's premisses and whose consequent is the argument's conclusion) that is necessarily true, even though it can have an instance with a true antecedent and can have an instance with an untrue consequent.

The received conception of consequence as formally grounded necessary truth-preservation can be articulated in substitutional, model-theoretic or schematic ways. To articulate the alternative conception of consequence as necessary truthtransmission in these ways, one permits treatment of extralogical constants like the name 'Socrates' in the same way as logical constants like the conjunction operator 'and' are treated and one rules out trivial consequences (Hitchcock 1998).

The substitutional, model-theoretic and schematic articulations of the two conceptions each replace the component of necessity in the original conception with a component of universality. The necessity with which truth is preserved or transmitted disappears, to be replaced by the universality with which a substitution or interpretation or instantiation produces an argument 
with a true conclusion when it has true premisses - against a background in which the universe is as it is, with no consideration of ways it might otherwise be. Equivalently, the impossibility of true premisses and an untrue conclusion disappears, to be replaced by the mere factual absence of a counter-example, where a counter-example is either a parallel argument with true premisses and an untrue conclusion or an interpretation on which the premisses are true and the conclusion untrue or an instance of a scheme of the argument that has true premisses and an untrue conclusion. The modal requirement in the truthtransmission conception that the argument can have true premisses and can have an untrue conclusion is replaced by the factual requirement that as a matter of fact at least one substitution or interpretation or instantiation produces an argument with true premisses and at least one produces an argument with an untrue conclusion.

John Etchemendy (1990) objected to the replacement of modality by universality. He argued that the model-theoretic conception of logical consequence, which is generally accepted by contemporary logicians as the gold standard against which other conceptions are to be measured, is an incorrect precization of the modal conception, one that both under-generates and over-generates consequences, missing consequences that obtain and inventing consequences where there are none. Gila Sher (1996) has replied that, because all the extra-logical constants in an argument's premisses and conclusion are subject to reinterpretation and variation of the domain is possible, the absence of a counter-interpretation is not just a matter of fact, but is a matter of logical necessity.

Sher's reply is however not open to defenders of the model-theoretic articulation of the truth-transmission conception of consequence, since on that conception not all the extra-logical constants in the premisses and conclusion of an argument need be subject to interpretation (or equivalently subject to reinterpretation if the extra-logical constants are already interpreted, as in arguments in a natural language). Consider for example the argument:

(4) Napoleon ruled France; Napoleon was exiled to Elba; so Napoleon was short.

Intuitively, the conclusion of this argument does not follow from its premisses: although Napoleon was in fact short, this fact does not follow from the biographical facts mentioned in the premisses. Yet the model-theoretic articulation of the truthtransmission conception implies that it does follow, since there is no re-interpretation of the name 'Napoleon' on which the 
premisses are true and the conclusion untrue (because nobody other than Napoleon ruled France and was exiled to Elba, and Napoleon was in fact short), even though the "re-interpretation" of 'Napoleon' as the name of Napoleon produces an argument with true premisses and the re-interpretation of 'Napoleon' as the name of Giscard d'Estaing produces an argument with an untrue conclusion. The model-theoretic articulation of the truthtransmission conception of consequence thus over-generates consequences. Furthermore, the substitutional and schematic articulations fare no better, since no substitution for the word 'Napoleon' will produce an argument with true premisses and an untrue conclusion and no instance of the schema 'person $x$ ruled France; person $x$ was exiled to Elba; so person $x$ was short' has true premisses and an untrue conclusion, even though in each articulation the non-triviality requirement is met. In a previous article (Hitchcock 1998, p. 32), I raised but did not answer the question how closely the model-theoretic, substitutional and schematic specifications of the truth-transmission conception of consequence fit our intuitive judgments of when a conclusion follows from stated premisses. The Napoleon argument in example (4) makes the answer clear. All three articulations are too loose a fit: they count conclusions as following when intuitively they do not follow. And the articulations are not on solid enough ground to over-rule our intuitive judgments about arguments like the Napoleon argument.

The crucial question for theoretical purposes is to figure out what is wrong with the Napoleon argument. Its premisses are impeccable: both true and known (independently of knowledge of the conclusion) to be true. Its conclusion is also true. There is also topical overlap, so the premisses cannot be stigmatized as lacking relevance in the sense in which relevance logicians make relevance a necessary condition for entailment. The premisses are evidently irrelevant to the conclusion in some broader sense that still needs theoretical articulation. It does not seem very illuminating, for example, to say that the premisses are not germane to the conclusion and have no bearing on it (Johnson and Blair 1993, p. 324) or that the truth of the premisses provides no basis for supposing that the conclusion is true, or indeed for supposing that it is false (p. 55). In the context of a conception of following as broader than following logically, we need to know in virtue of what feature of the Napoleon argument its premisses are non-germane to its conclusion, have no bearing on it, and provide no basis if they are true for supposing that the conclusion is true.

Unfortunately, the account of premissary relevance in (Hitchcock 1992) is not much help. According to that account, a premiss is irrelevant to a conclusion for which it is offered as 
support if it cannot ineliminably be put together with other at least potentially accurate information to provide a set of premisses that is sufficient to justify the conclusion (p. 260). But the premisses of the Napoleon argument can be put together ineliminably with the argument's associated material conditional to produce a formally valid argument. And the associated material conditional is not just potentially true; it is actually true and known to be true: a quick check of reputable sources will tell us that the associated material conditional has a true consequent (Napoleon was short), and hence is true. If the account of relevance in (Hitchcock 1992) is to be rescued, we need some account of why this formally valid expanded argument with premisses known to be true is not sufficient to justify its conclusion. On reflection, the problem appears to be that the added premiss (the material conditional associated with the original Napoleon argument) cannot be known to be true independently of knowing that the conclusion is true, so that the argument cannot produce knowledge of the truth of its conclusion. In view of this problem, the account of relevance in (Hitchcock 1992) needs to be modified by requiring for relevance that one can discover that the other potentially accurate information is actually correct without assuming the truth of the argument's conclusion. On the modified account, then, a premiss is relevant to a conclusion for which it is offered as support if and only if there is a set of premisses that (a) when combined with the relevant premiss are sufficient to justify the conclusion, (b) are not jointly sufficient by themselves to justify the conclusion, (c) are at least potentially accurate, and (d) if accurate can be discovered to be accurate without assuming the truth of the conclusion.

The question is how to modify or replace the substitutional, model-theoretic and schematic articulations of the truth-transmission account of consequence so as to capture these partly epistemological constraints on relevance. On the surface, the Napoleon argument seems to meet the conditions under which a conclusion follows from given premisses. It has a covering generalization that is not only true, but known to be true: Every ruler of France who was exiled to Elba was short. Further, this covering generalization is non-trivially true: there is at least one ruler of France who was exiled to Elba (namely, Napoleon) and there is at least one person who was not shortfor example, Giscard d'Estaing. But the non-trivial truth of this covering generalization does not license those who know of it to draw the conclusion from the premisses. Why not? One salient fact about the argument, already mentioned, is that, if you did not already know that Napoleon was short, the argument would give you no reason to believe that he was. This fact corresponds 
to the fact that our only basis for knowing that the argument's associated material conditional is true is that we already know that the conclusion is true. A fortiori, the only way to establish the truth of its generalization is to show for each instance where the antecedent is true that in this case the consequent is also true. One way to test this supposition is to consider a hypothetical case, e.g. another ruler of France who was not short, such as Jacques Chirac. If Chirac were exiled to Elba, he would not thereby become short. Nor is there any reason for restricting exrulers of France eligible for exile to Elba to those who were short. It seems then that a crucial requirement for a conclusion to follow from given premisses is that it has a covering generalization that is not only non-trivially true, but also can be known to be true independently of knowledge of truth of the conclusion. And it appears that we know that an argument has a true covering generalization independently of knowledge of the truth of the argument's conclusion if and only if we know that the covering generalization holds not just for actual cases that satisfy its antecedent but also for hypothetical cases that might satisfy it.

Consider another example:

(5) Abraham Lincoln was a president of the United States. So Abraham Lincoln was a man.

As a matter of fact, every previous president of the United States has been a man. But if we require an inference-licensing covering generalization to hold for hypothetical cases that might satisfy its antecedent, the fact that every previous president of the United States has been a man does not license us to infer from Abraham Lincoln's presidency that he was a man. For there is no rule against a woman being elected president of the United States. And indeed, counterfactually, if Walter Mondale had defeated Ronald Reagan in the 1984 US presidential election, and had then died in office, his running mate Geraldine Ferraro would not have become a man simply by succeeding him in the office of US president. The generalization that all previous US presidents have been men does not hold for all possible previous US presidents, even though it holds for the actual ones. This limitation corresponds, it seems, to the fact that the only way we can determine that every previous president of the United States has been a man is by discovering, directly or indirectly, about each of the 39 previous presidents that he was a man. The generalization cannot license an inference to the maleness of a particular previous president because our knowledge of its truth rests on already knowing that the particular previous president was a man. 
It is tempting to identify the requirement that an argument's true covering generalization supports counterfactual instances with a requirement that the argument has a true lawlike covering generalization. The covering generalization of the Socrates argument of example (3), that every human is mortal, is law-like if it is true. And such philosophers of science as Ernest Nagel have held (1961, pp. 71-72) that a singular counterfactual conditional holds if and only if the indicative form of its consequent follows logically from the indicative form of its antecedent in combination with a law and the requisite initial conditions for the law. The law would thus be a generalization of the indicative counterpart to the singular counterfactual conditional, with its antecedent supplemented by a statement of initial conditions. But requiring a law-like covering generalization may be too demanding. Consider the argument:

(6) Obama lives in the White House, so he lives in Washington.

Intuitively, the conclusion of this argument follows from the premiss: from the fact that someone lives in the White House, we are entitled to conclude that this person lives in Washington. The reason, of course, is that the White House is located in Washington. However, neither this fact nor the generalization based on it is law-like. The White House, i.e. the residence of the president of the United States, could have been built somewhere else. Or the political boundaries might be different, with Washington and the District of Columbia divided up among the surrounding states, with each of them giving their portion of present-day Washington its own name. Nevertheless, given that at present the White House is in Washington, the generalization that whoever lives in the White House lives in Washington supports counterfactuals. If John McCain lived in the White House, he would live in Washington. If Vladimir Putin lived in the (US) White House, he would live in Washington. And so on. It should be noted in making these counterfactual judgments that the generalization is being taken to hold only for the present, conceived as a short indefinitely bounded stretch of time surrounding the time of its inscription; it could not license for example an inference from the claim that the 50th president of the United States will live in the White House to the conclusion that he or she will live at that time in Washington, DC, since either the location of the president's residence or the boundaries of Washington, DC might have changed between now and then in such a way as to falsify the generalization that whoever lives in the White House lives in Washington, DC. The time-boundedness of the covering 
generalization of the Obama argument immediately shows that it is not a natural law. Nevertheless, it supports counterfactual instances. Hence, since one could not know that counterfactual instances of a universal generalization were true if one could discover the truth of the generalization only by discovering the truth separately of each of its instances, the covering generalization of the Obama argument is known to be true independently of knowledge of the truth of the conclusion that Obama lives in Washington.

If one insists that any covering generalization that licenses an inference must be law-like, then one would be obliged to treat the Obama argument as having an unexpressed premiss, assumed to be mutually believed by both arguer and intended audience, that the White House is located in Washington, DC. With the addition of this premiss to the stated premiss, the conclusion would follow in virtue of the law-like generalization that whoever lives in a building that is located in a certain municipality lives in that municipality. But there seems to be no theoretical advantage to this approach over the approach of treating non-law-like covering generalizations that support counterfactual instances as licensing inferences, even if the license is temporally constrained. And, practically speaking, it is easier to ask directly whether an argument has a true covering generalization that supports counterfactual instances than to ask whether it can be supplemented with additional correct information in such a way that the expanded argument has a true law-like covering generalization. With this latter approach, for example, one must make sure that the conclusion does not follow from the additional correct information independently of the argument's stated premisses. Further, treating the conclusion of the Obama argument in example 6 as following just from the stated premiss corresponds better to the phenomenological fact that one would not use any other premiss than the stated premiss in reasoning for oneself from it to the stated conclusion.

\section{Second reformulation: following as counterfactual- supporting truth-transmission}

Thus it appears that, in the case of non-logical consequence, we cannot capture the consequence relation through a merely universal condition, whether expressed substitutionally, modeltheoretically or schematically. But, contrary to the position adopted in (Hitchcock 2009), the non-logical consequence relation need not hold as a matter of nomic necessity. It is enough if the universal condition holds counterfactually, of any individual supposed to satisfy its antecedent. Necessarily true 
universal covering generalizations do hold counterfactually, and as we have seen the necessity of the generalization need not be semantic but might be for example physiological or constitutional. But, as the Obama argument of example (6) shows, some universal covering generalizations hold counterfactually even if they are not nomically necessary.

Substitutional and model-theoretic articulations of the consequence relation cannot be modified to express the requirement that a universal condition holds counterfactually. But schematic articulations can. We can revise the schematic articulation of the truth-transmission conception of consequence to read as follows: A conclusion is a consequence of given premisses if and only if the argument is an instance of an argument scheme, which may or may not be purely formal, that has no actual or counterfactual instances with true premisses and an untrue conclusion, even though it has an instance with true premisses and an instance with an untrue conclusion.

The counterfactual-supporting version of the schematic articulation of the truth-transmission conception of consequence automatically addresses a limitation of standard substitutional and schematic articulations - namely, the limitation that an argument may lack a counter-example because of the limitations of the language in which it is expressed. In opening up a space for instances that are hypothetical rather than actual, we allow that the language may have no name for such merely hypothetical instances. We can accommodate such presently nameless possible instances by allowing the addition of new names to the language in which the argument is expressed.

Counterfactual-supporting truth-transmission in virtue of an argument scheme depends on the truth of a covering generalization of the argument that will support counterfactual instances. The generalization might be physically contingent, like the generalization that whoever lives in the White House lives in Washington. But it must support counterfactual instances. A true contingent generalization that does not support counterfactuals will not license an inference from its antecedent to its consequent. Thus the fact that every president of the United States has been a man does not license an inference from Abraham Lincoln's having been president of the United States to his having been a man, for the generalization about the sex of American presidents has false counterfactual instances: if Walter Mondale had been elected U.S. president in 1984 and had died in office, to be succeeded by his running mate Geraldine Ferraro, she would not have been a man.

It would make things theoretically neat if in general knowledge of the truth of true universal generalizations that do not support counterfactual instances had to rest ultimately on know- 
ledge of the actual instances that fall under them. But consider the universal generalization that all spheres of gold are less than one mile in diameter, constrasted to the law-like generalization that all spheres of uranium are less than one mile in diameter (Carroll 2011). Here our belief in the universal generalization does not rest on knowledge of the diameter of all the actual spheres of gold, past, present and future, but on knowledge of facts about the cost, scarcity and uselessness (for all but ornamental and fetishistic purposes) of gold. Thus an argument like:

(7) This sphere is pure gold, so its diameter is less than a mile.

though its conclusion does not follow just from its stated premiss, could be rescued by attributing to it an unexpressed premiss that every sphere of gold has a diameter less than a mile.

The requirement that a generalization licensing an inference support counterfactual instances implies an asymmetry in the treatment of real-life arguments. If someone were to argue that Abraham Lincoln was a man, because he was president of the United States, one could as far as I can see get the conclusion to follow from the premiss only by attributing to the argument an unstated premiss that all previous presidents of the United States were men. But, in contrast to the gold argument in example (7), this maneuver would not make the argument respectable, since any epistemic justification for the added premiss would have to appeal ultimately to the information in the conclusion.

The theoretical asymmetry in the treatment of formally invalid arguments is however not as extensive as one might imagine. Occasionally people advance arguments whose conclusion follows, if at all, in virtue of a merely contingent generalization. But, rather surprisingly, it seems that these merely contingent generalizations support counterfactuals. Consider the following remarks by a caller to a radio phone-in show soon after the invasion of Iraq in March 2003, at a time when there were reports of Iraqi families being told they will be murdered if they don't fight:

(8) I think you will make a very poor soldier if you put a gun on his head or on his family and say, "Go and fight". We have to acknowledge that the Iraqis are fighting an aggression whether rightly or wrongly. They think that they are going to be occupied. And even the US army generals are acknowledging that they are having a stiff resistance. You do not get stiff 
resistance from soldiers who are under duress. (Hitchcock 2010a, p. 41.)

The context makes clear that the caller is arguing that the Iraqi soldiers are not fighting under duress, a conclusion that follows almost logically from his last two statements. The preceding statements appear to give two additional independent arguments for the same conclusion. If we take the first statement as the premiss of one of those arguments, and supply the implicit conclusion, we get the following argument:

(9) ...you will make a very poor soldier if you put a gun on his head or on his family and say, "Go and fight"; so the Iraqi soldiers are not fighting under duress.

If we acknowledge the semantic connection between fighting under duress and being told to go and fight with a gun to one's head or on one's family, we can see that this argument is an instance of the schema 'People who are $F$ are very poor soldiers, so the Iraqi soldiers are not $F$ '. The universally generalized material conditional associated with this schema turns out to be logically equivalent to the statement that the Iraqi soldiers are not very poor soldiers; for the proof, see the appendix. This statement is what a skilled argument analyst would intuitively attribute to the caller as an assumption involved in using his general point about very poor soldiers to support a claim about the Iraqi soldiers in particular. But, even though the covering generalization is not law-like, it does support counterfactuals. If the Iraqi soldiers are not very poor soldiers, then, if short people were very poor soldiers, then the Iraqi soldiers would not be short. And so on.

Thus, contrary to the approach recommended in (Freeman 2011a, pp. 186-189), the fact that an argument lacks a true nomically necessary covering generalization does not require adoption of the unexpressed premiss approach in order to understand and then evaluate the argument. A true nomically contingent covering generalization will license the inference in the stated argument if it supports counterfactual instances. Even singular contingent statements can license inferences, as in the Iraqi soldiers argument of example (9). In particular, there is no need to revert to an unexpressed premiss in order to understand and evaluate the following artificial argument discussed by Freeman (2011a, p. 183):

(10) All humans are mortal, so Socrates is mortal. 
The argument is an instance of the schema: All humans are $F$, so Socrates is $F$. The corresponding universal covering generalization is that Socrates has every property that all humans have. By parallel reasoning to that used for the Iraqi soldiers argument of example (9), this generalization is logically equivalent to the contingent singular statement that Socrates is human. Assuming that this statement is true, it will license the inference in the Socrates argument of example (10), provided that the universal generalization to which it is logically equivalent supports counterfactual instances. And in this case it does. If all humans had green skin, Socrates would have green skin. If all humans had blue eyes, Socrates would have blue eyes. And so on. (The Socrates argument of example (10) is of course artificial; it is hard to imagine someone putting it forward seriously in an attempt to establish its conclusion. But one can readily imagine a parallel argument with the name 'Jesus of Nazareth' replacing 'Socrates' being seriously advanced by a critic of a certain position in Christian theology.)

As far as I can see, people do not reason and argue in accordance with argument schemes whose corresponding universal generalization does not support counterfactual instances. To put the point another way, for all but one of the arguments I have collected in two rounds of random sampling of arguments (Hitchcock 2002, 2010a), resulting in more than 100 inferences for evaluation, I have been able to construct a covering generalization that, if true or otherwise acceptable, would apparently hold for counterfactual instances. To bolster this claim, it would be necessary to get independent and unbiased judgments from at least two people as to whether a given universal generalization if true would support counterfactual instances. Such judgments may require real-world knowledge, as in the case of a sphere of gold versus a sphere of uranium. But, despite ongoing disputes about the truth conditions for counterfactual singular conditionals (Lewis 1973, Pearl 2000, Arregui 2009), there seems little disagreement about the truth value of counterfactual instances of a true universal generalization in a world otherwise much like ours or with the same invariant causal relationships as ours. For example, the reader should readily agree that Jacques Chirac would not be short if he not only was a former ruler of France but also had been exiled to Elba; that Socrates would have had green skin if all humans had green skin; that a sphere of gold would not have a diameter less than a mile if it had a circumference of four miles; and so on for the other examples in this article. 


\section{Elaboration and extensions of counterfactual-supporting truth-transmission}

On the counterfactual-supporting truth-transmission account, then, a conclusion follows from given premisses if and only if the argument is an instance of an argument scheme, which may or may not be purely formal, that has no actual or possible instances with true premisses and an untrue conclusion, even though it has an instance with true premisses and an instance with an untrue conclusion.

This account, it turns out, needs elaboration and extension, in four respects.

5.1. Restrictions on the range of the variables in an argument's schema: First, in testing to see whether an argument has a counterfactual-supporting covering generalization that is non-trivially true, we may need to restrict the range of the variables in a generalization under consideration. Such restrictions are implicit in the examples of covering generalizations already given, where the range of variables is restricted to persons, countries, places and so on. To take another example: if someone argues that marijuana should be legalized on the dual ground that it is less harmful than alcohol and that alcohol is justifiably legal, it is reasonable to restrict the variables in the covering generalization to psychotropic drugs (Hitchcock 1985). Such restrictions presuppose the background information that the name or other term over which one generalizes falls within the specified range: Napoleon is a person, France is a country, marijuana and alcohol are psychotropic drugs, and so forth. Background information of this sort can be treated as an unstated premiss if one wishes, or more accurately as an unstated presupposition: in a debate about legalizing marijuana, one does not need to state that marijuana is a mind-altering drug.

5.2. Generalization from truth to acceptability: Second, some may balk at assigning truth-values to deontic generalizations. To accommodate such sensitivities, we can replace the word 'true' in the articulation of the truth-transmission conception of consequence with a word like 'acceptable' or 'justifiable' (in their normative senses), treating truth as a property that confers acceptability or justifiability in the intended sense.

5.3. Allowance for conclusions that are not assertives: Third, allowance needs to be made for conclusions that are not assertives. One can argue for any of the kinds of speech acts distinguished by Searle (1979), including commissives, directives, expressives, declaratives and suppositives (Hitchcock 2006). For 
example, the following exchange on a radio phone-in show about the epidemic of Sudden Acute Respiratory Syndrome $(\mathrm{SARS})^{1}$ in Toronto in the spring of 2003 concludes with an argument for a question:

(11) Caller (Gina from Toronto): - - Hi. I wanted to speak about the SARS.

Roy (program host): - Yes. Go ahead, please.

Gina: -OK. On the weekend they had... were looking for court orders for two people who had not obeyed the quarantine. They now have a student who cut short her quarantine after ten days to write an exam. She's now ill, and they have now 25 students and a teacher, I believe. So, considering how the government mishandled Walkerton ${ }^{2}$ and the East Nile virus, where... it's worked out OK with SARS, I realize they're not saying an epidemic, but last week before they really, really knew and the TTC [Toronto Transit Commission-DH] driver wanted to wear a mask, where was their union? They said their hands were tied, that they can't do anything when the Board of Health says this, but why do people so blindly believe government officials?

Roy: - Well, you know, I think when it comes to an issue like SARS, you do look to official explanations and official sources...

Gina: - Yes. Just like Walkerton and the East Nile virus, which they mishandled

Roy: -West Nile.

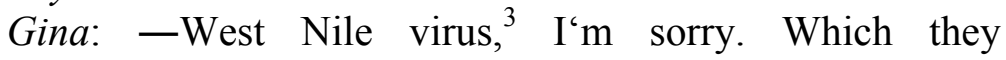
mishandled. So why do you want to believe them now? (Hitchcock 2010a, p. 55)

\footnotetext{
${ }^{1}$ SARS was a new, highly contagious respiratory viral infection that turned out to have a fatality rate of about $15 \%$. Public health authorities reacted by imposing a quarantine on anybody suspected of being at risk for contracting the disease. The disease was eventually eradicated as the result of an aggressive world-wide campaign to stamp it out.

2 Walkerton is a small town in Ontario whose water supply became contaminated in May 2000. Almost half the population became ill, and seven people died. A study put the cost of dealing with the tragedy at $\$ 64.5$ million. (http://www.cbc.ca/news/background/walkerton/; accessed 201103 14)

${ }^{3}$ In the summer of 2002, 19 people in the southern part of Oakville, Ontario were hospitalized for diseases caused by the West Nile virus, which is transmitted to humans by mosquito bites.

(http://www.health.gov.on.ca/english/public/pub/ministry_reports/wnv_rep_2 003/wnv rep03.html; accessed 201103 14).
} 
Gina's concluding sub-argument, supporting her question, "Why do people so blindly believe government officials?" runs as follows:

(12) Premiss: The government mishandled Walkerton and the West Nile virus.

Intermediate conclusion: Why do people so blindly believe government officials <on this public health crisis$\mathrm{DH}>$ ?

We can construct a covering generalization in the usual way, recognizing the shared background information that Walkerton and the West Nile virus were public health crises: If a government mishandled two previous public health crises, why do people so blindly believe what officials of the government say on another public health crisis? In evaluating whether this covering generalization is acceptable, we need to judge the force of the 'why' question. Taken literally, it is a request for an explanation of people's blind belief in the statements of government officials. What motivates such a request is the presupposition that such blind belief makes no sense. The acceptability of the question is thus a function of the prima facie foolishness of blindly believing statements about a public health crisis by officials of a government that recently mishandled other public health crises.

As with this example, one can develop criteria for the acceptability of speech acts of all types, criteria that can be used in judging whether a commissive or directive or expressive or declarative follows from the reasons given in its support.

5.4. Allowance for rebuttable inferences: Fourth, allowance needs to be made for rebuttable inferences, where the conclusion does not follow definitely from the premisses but is merely made probable or possible or presumptively acceptable by them. Such inferences are rebuttable in the sense that further information compatible with the premisses can make the conclusion false or otherwise unacceptable. A conclusion that follows definitely from the premisses, on the other hand, is not rebuttable in this sense; if it is unacceptable, there must be something wrong with at least one premiss. It is however underminable, given the non-triviality requirement for transmission of acceptability. The information that Arthur is either a farmer or a grocer but is not a farmer necessitates as a consequence that Arthur is a grocer, but additional information that Arthur is a farmer undermines the inference. It does not follow necessarily from the premiss set A Arthur is a farmer, Arthur is not a farmer, Arthur is either a farmer or a grocer $\}$ that Arthur is a grocer. 
To signal a rebuttable inference, arguers sometimes use modal auxiliaries or adverbs, as in the following argument from a caller to a phone-in radio show:

(13) ... when someone is purchasing a puppy, many times they are going to a breeder that's just in it for profit, so the puppy's already starting out with maybe not a good head start. (Hitchcock 2010a, p. 18)

The caller acknowledges that not every puppy bought from a breeder just in it for profit lacks a good head start. The qualifier 'maybe' reduces the strength of the inference claim, which thus needs for its support only a counterfactual-supporting existential generalization that some animals bought from breeders just in it for profit do not get a good head start.

With these four complications, the truth-transmission account, which should now be called an acceptability-transmission account, appears capable of handling all inferences. We can sum it up as follows. A conclusion follows from given premisses if and only if an acceptable counterfactual-supporting generalization rules out, either definitively or with some modal qualification, simultaneous acceptability of the premisses and non-acceptability of the conclusion, even though it does not rule out acceptability of the premisses and does not require acceptability of the conclusion independently of the premisses. (The account is framed in terms of the non-acceptability of the conclusion rather than its unacceptability, to allow for the possibility that a conclusion is neither acceptable nor unacceptable, because it is neither worthy or acceptance nor worthy of rejection.) An inference claim is thus the claim that a counterfactual-supporting covering generalization is non-trivially acceptable.

This consequence relation has structural properties that deserve investigation. For example, it is transitive only under certain conditions, and obeys the cut rule only under certain conditions. Hence it implies restrictions on the chaining of arguments together to support a final conclusion by means of one or more intermediate conclusions drawn along the way. The present paper prescinds from investigation of these restrictions, because of limitations of space and time. In a recent investigation of rebuttable inference, Verheij (2010) shows that a non-monotonic consequence relation in "reason-based argumentation" has seven properties, which he calls logical equivalence, restricted reflexivity, antecedence, right weakening, conjunctive cautious monotony, mutual attack and conjunctive cumulative transitivity. It needs to be investigated which of these properties belong to consequence conceived as acceptability-transmission licensed by a non-trivially acceptable counterfactual-supporting covering generalization. 
If one insists that a conclusion follows from given premisses only if it follows formally from them, then one can treat the inference claim of an argument that is not formally valid as the claim that the argument has as an unstated premiss a counterfactual-supporting covering generalization that is nontrivially acceptable. Hence, if one thinks that formally invalid arguments have a gap between premisses and conclusion that needs to be filled by a gap-filling implicit assumption (Ennis 1982), then one will supply as the gap-filler the most non-trivially plausible counterfactual-supporting covering generalization of the stated argument.

\section{A sceptical rejoinder}

Sceptics can counter that this account of inference claims is unnecessarily complicated, that the inference claim of an argument is just its so-called "associated conditional" (Hitchcock 1985), i.e. the singular conditional whose antecedent is the conjunction of the premisses and whose consequent is the conclusion. Doesn't the connective 'if' simply mean that the consequent follows from the antecedent, as Stoic logicians long ago maintained (Diogenes Laertius 7.71)? And don't theorists of argument reconstruction object that supplying an argument's associated conditional as its unstated gap-filling premiss is merely reiterative, not really informing us of the substantive assumption used or needed to infer the conclusion?

Let us grant that in at least one of its uses a singular indicative conditional sentence means that its consequent follows from the antecedent. In fact, in the ancient dispute about the truth-conditions for singular indicative conditionals, it was common ground that a conditional is true when its consequent follows from its antecedent (Sextus Empiricus 2.112; cf. Barnes 2007, pp. 125-126). The dispute was about what it took for this condition of following to be met. The earliest proposal was that of the logician Diodorus Cronus, who proposed that a true conditional was one that neither could nor can begin from a truth and end in a falsity (Sextus Empiricus 2.115). This modal conception would imply that a conclusion follows from given premisses if and only if it was and is impossible for the premisses to be true and the conclusion false. The present conception of the consequence relation is similar, with the additional requirement that the impossibility be non-trivial (i.e. not due to the impossibility that the premisses are true and not due to the impossibility that the conclusion is false), the clarification that the impossibility need not be logical or semantic (and indeed can be established by any counterfactual- 
supporting covering generalization), allowance for the ruling out of true premisses and a false conclusion to hold only for a specious present rather than omni-temporally, the expansion of the property of truth to other kinds of acceptability, and the recognition of modally qualified rebuttable consequences. I propose then, following the ancient tradition, to take the present account of the consequence relation to be also an account of the truth conditions of a singular indicative conditional, in at least one of its senses. In this sense, a singular indicative conditional is definitively acceptable if and only if it has a counterfactualsupporting generalization that is non-trivially acceptable. It is acceptable in some qualified way if and only if it has a counterfactual-supporting generalization that is non-trivially acceptable in the same qualified way.

Of course, some philosophers of language, starting with Diodorus' own pupil Philo of Megara (Sextus Empiricus 2.113114 ) and continuing as recently as in the work of Paul Grice (1989, pp. 58-85), maintain that the singular indicative conditional is true if and only if it does not have a true antecedent and a false consequent. But, although Philo thought that the consequent of a conditional with such truth conditions follows from its antecedent, contemporary logicians and philosophers of language generally reject this claim. They take the medieval conception of a consequentia materialis as a consequence that holds unless the premisses are true and the conclusion false (Kneale and Kneale 1962, pp. 274-297) to reflect confusion between the truth of a conditional and the validity of an argument from its antecedent to its consequent. Likewise, they regard as unfortunate the use by Whitehead and Russell in Principia Mathematica (1910-1913) of the phrase 'material implication' for the Philonian truth-functional conditional, since they generally follow C. I. Lewis (1912) in regarding the truth-functional conditional as not capturing the sense in standard English of the word 'implies', which signifies the converse of the relation of following. The problem with construing the Philonian conditional as expressing the implication of its consequent by its antecedent, it is generally thought, is the so-called "paradoxes of material implication": a falsehood would imply anything and anything would imply a truth.

\section{Anti-generalist alternatives}

Some contemporary theorists of argumentation have, however, defended the view that the inference claim of an argument is its associated singular conditional, taken by some of them to be 
truth-functional (i.e. Philonian or "material") and by others to be sui generis. Others have argued, within the unexpressed premiss approach, that either always or sometimes the unexpressed premiss of an argument that is not formally valid is just the argument's associated singular conditional, whether truthfunctional or sui generis. I shall consider each of the four views.

8.1 Bermejo Luque: Lilian Bermejo Luque (2006, 2011a) interprets the inference claim made in the complex speech act of arguing as the claim that the argument's associated material conditional is true. Her interpretation seems incorrect on its face, for the mere absence of the circumstance that the argument's reasons are true and its conclusion untrue seems weaker than the circumstance that the conclusion follows from those reasons. Suppose, for example, that someone were to argue:

(14) 8 is divisible by 2, so 8 is divisible by 4 .

This is clearly a bad argument, even though it has a true premiss and a true conclusion. You cannot legitimately infer from the fact that 8 is divisible by 2 that 8 is also divisible by 4 , even though as a matter of fact it is true that 8 is divisible by 4 . Thus the inference claim in the divisibility argument of example (14) is false. But the associated material conditional is true, because it has a true consequent.

In this counter-example, the conclusion is known to be true independently of the argument put forward in its support. Bermejo-Luque tries to ward off this sort of counter-example by remarking that an argument's associated material conditional

is to be valued under the argumentative conditions in which it arises, namely, that the reason alleged in the argument (whose content is the antecedent of the conditional) is supposed to be true or highly acceptable, and also that we have not already independently determined the real value of the claim for which we argue (whose content is the consequent of the conditional). These conditions suffice to free us from the paradoxes of material implication... (Bermejo-Luque 2006, p. 79; cf. her 2011a, p. 79.)

So we are to construe the supposed counter-example as an argument presented in a situation where it is supposed to be true that 8 is divisible by 2 , but we have not already determined independently whether 8 is divisible by 4 . To make such a situation plausible, let's vary the example slightly to one where the arithmetical premiss has been determined to be true, the 
arithmetical conclusion not yet determined to be true, and the inference is apparently incorrect. An example might be the following argument:

\section{(15) 79,974 is divisible by 3, so 79,974 is divisible by 9 .}

According to Bermejo-Luque, the fact that the premiss of this argument is supposed to be true (and can in fact easily be checked to be true) but that we have not yet determined whether the conclusion is true (because we have not yet tried to divide 79,974 by 9) frees us from the paradoxes of material implication when we come to appraise the argument's associated material conditional. To avoid confusion with other senses of the conditional, let us consider the situation in terms of the logically equivalent negajunction 'Not both 79,974 is divisible by 3 and 79,974 is not divisible by 9.' Given that we know that the first of the two conjuncts in this negated conjunction is true, the easiest and most direct way to determine whether the negajunction is true is to check whether the second conjunct is also true. If the second conjunct is also true, then the whole conjunction is true, the associated negajunction is false and the conclusion (on Bermejo Luque's account) does not follow. If the second conjunct is false, then the whole conjunction is false, the associated negajunction is true and the conclusion (on Bermejo Luque's account) does follow. The fact that we have not already determined the value of our conclusion does not bar us, when it comes to appraising the argument's associated material conditional, from making such a determination independently of the argument offered in its support. If we have a way of making such an independent determination, and that determination yields the result that the conclusion is true, we will rightly conclude that the associated negajunction is true. Thus, on Bermejo-Luque's account, every act of arguing for a conclusion whose propositional content can be determined to be true independently of the propositional content of its premisses makes a true inference-claim: its conclusion does in fact follow from the premisses offered in its support.

This is a clearly unacceptable consequence, as we can readily see by constructing simple examples of arguments with an obviously true conclusion and an obviously irrelevant premiss. Consider:

(16) Snow is white, so grass is green.

This is not a good argument, even though both its premiss and its associated negajunction are both known to be true. The conclusion that grass is green simply does not follow from the 
premiss that snow is white, which is obviously totally irrelevant to the conclusion. The word 'so' when used inferentially implies, as part of its meaning and not as some pragmatic implicature of its ordinary use, that the statement preceding it is relevant to the statement following it, in the sense explicated in (Hitchcock, 1992) and qualified earlier in the present article, that it helps to establish the truth of the conclusion. The truth of an argument's associated negajunction is not sufficient to secure such relevance.

In a symposium on Bermejo-Luque's Giving Reasons, Freeman (2011b) and Pinto (2011) raise similar objections to Bermejo-Luque's identification of the propositional content of an arguer's inference claim with the argument's associated material conditional. In reply, Bermejo-Luque reiterates and elaborates her position as follows:

... following Grice's account of conditionals, I take inference-claims of the form "if 79974 is divisible by 3, then 79974 is divisible by 9" to be conversationally inappropriate, but not false. In other words, I think that an act of arguing such as "79974 is divisible by 3 , therefore 79974 is divisible by 9 " is semantically correct, but pragmatically flawed because the reason is irrelevant. To my mind, this kind of irrelevance is pragmatic: we put forward a reason in order to show a target claim to be correct, but the reason does not work for this end. On Grice's account, the only circumstances in which it is appropriate to assert a conditional is where the speaker is ignorant of the truth values of $\mathrm{R}$ [the reason- $\mathrm{DH}$ ] and $\mathrm{C}$ [the conclusion- $\mathrm{DH}$ ], but believes that if $\mathrm{R}$ happens to be true, $\mathrm{C}$ will as well. (Bermejo-Luque 2011b, pp. 229-230.)

This restatement helps to defuse the obvious objection to Bermejo-Luque's interpretation of an arguer's inference-claim as the claim that the argument's associated material conditional is correct. On her account, a good act of arguing requires not just that the arguer's inference-claim be true but that the arguer be in a position to assert it. That is, the arguer must have a basis for asserting it other than the denial of the reason or the assertion of the conclusion. Bermejo-Luque herself acknowledges that this basis can include (2011a, p. 65), and indeed will consist in (p. 198), general rules or general facts from which the material conditional follows. Thus in the end her position is not far from that of the present article, except that she rests the claim that an argument has a covering generalization on the pragmatics of advancing the argument rather than on the semantics of inferential particles and phrases. Later in this 
article, in the discussion in section 8.3 of Janne Maaike Gerlofs' position, I will return to the question whether justification of a material conditional without using a paradox of material implication requires appeal to some generalization of it.

8.2. Verheij: Bart Verheij (2006, p. 186) also identifies the inference-claim of an argument with its singular, ungeneralized associated conditional. Verheij takes an argument to express that its premisses collectively support its conclusion, and takes this support relation to be expressed by the conditional sentence 'if $<$ the premisses $>$, then $<$ the conclusion $>$ '. For example, in the following argument:

(17) Harry was born in Bermuda, so Harry is a British subject.

the claim that the premiss 'Harry was born in Bermuda' supports the conclusion 'Harry is a British subject' is expressed by the sentence:

(18) If Harry was born in Bermuda, he is a British subject.

Unlike Bermejo-Luque, however, Verheij refuses to identify an argument's inference claim with the material conditional, because the material conditional is truth-functional:

...a material conditional is truth-functional: its truth value is determined by the truth values of the conditional's antecedent and consequent... The conditional 'If D [data$\mathrm{DH}$ ], then $\mathrm{C}$ [conclusion-DH]' implied by an argument 'D. So C' should however intuitively reflect some relation between $\mathrm{D}$ and $\mathrm{C}$ that is not captured by the truth values of D and C alone. (Verheij 2006, p. 187.)

Let us call Verheij's non-material, non-truth-functional singular conditional an 'inferential conditional,' since it expresses the condition that an argument's premisses support its conclusion, i.e. that it is legitimate to infer the conclusion from the premisses. Verheij does not give a complete account of the semantics of the inferential conditional. He tells us that it validates modus ponendo ponens; in other words, an argument from an inferential conditional and its antecedent to the consequent of the inferential conditional is formally valid. He tells us that one cannot derive an inferential conditional on the basis of logic alone (e.g. from a deduction of its consequent from its antecedent), but must always base its derivation on premisses. But he says very little about what premisses would 
entitle us to infer the truth of an inferential conditional. In fact, he claims that, if the logic of the inferential conditional were expressed in a natural deduction system, it would have the standard elimination rule for conditionals, namely modus ponendo ponens, but would have no introduction rule. The only derivation of an inferential conditional that he recognizes as legitimate is its derivation using modus ponendo ponens from a more complex inferential conditional of which the inferential conditional is the consequent. In particular, the inferential conditional associated with a particular argument follows from what he calls (following Toulmin (1958)) the argument's warrant, which is a conditional scheme expressed in ordinary language as a rule statement. For example, the inferential conditional (18) that Harry is a British subject if he was born in Bermuda follows from the following statement:

(19) A person born in Bermuda is a British subject.

The inferential conditional expressing that this statement (19) supports the original argument's associated inferential conditional (18) is the following statement:

(20) If a person born in Bermuda is a British subject, then Harry is a British subject if he was born in Bermuda.

The consequent of this second-order inferential conditional is according to Verheij an instance of its antecedent.

Verheij needs to complete his account of the semantics of the inferential conditional. In particular, since a rule statement like "a person born in Bermuda is a British subject" sounds awfully like a generalized material conditional, and the inferential conditional associated with an argument is supposed to be an instance of such a rule statement but not to be a mere material conditional, Verheij needs to tell us how a warrant differs from a generalized material conditional. The answer, I suspect, will be an account like the one I have been developing in this paper, that it must be a counterfactual-supporting generalization of the argument's associated material conditional. In that case, Verheij's singular inferential conditional will have just the meaning that I am attributing to singular indicative conditionals when they signify that their consequent follows from their antecedent.

8.3. Gerlofs: Janne Maaike Gerlofs works within the mainstream logical tradition according to which an argument that is not explicitly formally valid is to be reconstructed by supplying an unexpressed premiss whose addition will make the argument for- 
mally valid. She argues $(2009,2011)$ that in general the argument analyst should supply as the unexpressed "connecting" premiss the argument's ungeneralized associated material conditional. (In her (2009), she makes an exception for cases where what she calls the "connecting premise" is explicit. If the stated premiss is a singular indicative conditional and the conclusion is the consequent of that conditional, one needs to supply its antecedent as the unexpressed premiss; an example is the argument, "There is no reason to inform the Child Protection Office. If there is no evidence the father started the fire deliberately to hurt his children, there is no need to do so", where one should supply as the unexpressed premiss, "There is no evidence the father started the fire deliberately to hurt his children" (p. 86). If the stated premiss is a counterfactual conditional offered in support of the denial of its antecedent, one needs to supply the denial of its consequent as the unexpressed premiss; an example is the argument, "Daniel is no athlete. If Daniel were an athlete, he would have stamina", where one should supply as the unexpressed premiss, "Daniel does not have stamina." (p. 103).)

In defence of her position, Gerlofs points out that the associated material conditional does do the job of transferring acceptability from the expressed premiss to the conclusion, by means of the valid form of argument modus ponendo ponens. Given this role, she argues, the associated material conditional is what Davies (1979) calls a "knowledge conditional", defined as a conditional in which the antecedent contains accepted knowledge and the consequent a conclusion "deduced" (i.e. inferred) from this knowledge: in argumentation the antecedent is put forward as already accepted and the connecting premiss (whether expressed or unexpressed) is put forward as a means of transferring acceptability from the non-connecting premiss to the conclusion. Further, material conditionals derived using the paradoxes of material implication cannot be used as a connecting premiss. If the author of an argument defends its connecting premiss by appealing to the truth of its consequent, the reasoning is circular if the premiss is being used to transfer acceptability from its antecedent to its consequent and involves a contradiction if the connecting premiss is a counterfactual conditional being used to transfer unacceptability from its consequent to its antecedent (Gerlofs (2009), p. 107). Similarly, if the author defends the connecting premiss by appealing to the falsehood of its antecedent, the reasoning is circular if the premiss is being used to transfer unacceptability from its consequent to its antecedent and involves a contradiction if it is being used to transfer acceptability from its antecedent to its consequent. Thus the paradoxes of material implication are deprived of their sting. 
An argument's associated material conditional is the logical minimum among the statements that can be added to make an argument formally valid, in the sense that it follows logically from any statement whose addition as a premiss will make the argument formally valid without making a stated premiss redundant. In her (2011), Gerlofs argues that treating the connecting premiss of an argument as this logical minimum has heuristic advantages, in that it enables one to classify critical questions that one can raise about an argument and to determine whether critical questions posed for a given argumentation scheme cover all the points where a particular argument fitting the scheme can be questioned. She points out that the critical reactions to an argument, which correspond to the critical questions belonging to its argument scheme, can concern the acceptability of the argument's premisses, the ground for the logical minimum or the connection between the ground and the logical minimum.

Gerlofs' proposal is carefully articulated and defended, and deserves serious consideration. My suspicion is that, if one investigates the ways in which a singular material conditional can be defended, other than by denying its antecedent or affirming its consequent, one will discover that one needs to appeal to a counterfactual-supporting covering generalization, or to something logically stronger that implies a counterfactualsupporting covering generalization. If so, then, given the pragmatic constraints that Gerlofs imposes on the justification of an unexpressed connecting premiss, her position would turn out to be equivalent to mine: the argument as stated implies that it has a counterfactual-supporting covering generalization that is non-trivially acceptable.

Gerlofs herself proposes (2009, pp. 111-117) to evaluate connecting premisses by means of argument schemes, whose expression as a generalized conditional would provide what she calls the "ground" for the connecting premiss. Such schemes are in fact generalizations, at some level of abstraction, of the particular argument taken to fit them, and are taken to hold counterfactually and non-trivially, given satisfactory answers to the "critical questions" associated with them that pertain to the transfer of acceptability from premiss to conclusion (Hitchcock 2010b). Thus her position turns out to be equivalent to mine. But her only argument for restricting the justification of connecting premisses to an appeal to argument schemes is that an arguer cannot justify a connecting premiss by appealing directly to the truth values of its antecedent and consequent.

How can one justify a singular material conditional, other than by denying its antecedent or affirming its consequent? The typical strategy for proving a conditional is to assume its 
antecedent and derive its consequent. One can then discharge the assumption and assert the conditional on the basis of the assumptions other than the antecedent that were used in deriving the consequent from the antecedent. In a situation where we are given an argument from the antecedent to the consequent and are treating the material conditional as the logically minimal gap-filler, the assumptions enabling us to derive the consequent from the antecedent would serve as what the pragma-dialectical approach calls the "pragmatic optimum" (Van Eemeren and Grootendorst 1992, pp. 63-64). In general, an argument for some conclusion would transfer acceptability from the stated premisses to the conclusion if and only if the associated singular material conditional follows from acceptable assumptions none of which either are identical to or rely for their support on the conclusion. Thus, the inference claim of any argument is the claim that its associated singular material conditional follows from acceptable assumptions that are epistemically independent of the conclusion. It is clear that a generalization of the associated conditional that supports counterfactuals must be based on more than the truth of the consequent or the falsehood of the antecedent. What is not clear is that any assumptions epistemically independent of the conclusion that are sufficient for it to follow logically from the stated premisses must be at least as strong as some counterfactual-supporting generalization. However, two suggestions of epistemically independent assumptions other than a counterfactual-supporting generalization turn out to entail a counterfactual-supporting covering generalization. Bermejo-Luque suggested (personal correspondence) that a reason for "if you promised, you have to do it" (construed as a material conditional, i.e. a negajunction) may be something like the very definition of "promising". She also suggested that a reason for "if the litmus paper turned red, then the liquid in which it was dipped is an acid" may be something like a chemical explanation. Definitions and chemical explanations, however, although they are not covering generalizations, entail covering generalizations, which support counterfactual instances if the definition or chemical explanation is correct. So reasons of this kind imply that the author of the argument is committed to a covering generalization of its associated negajunction. These two attempts thus failed to find a way of deriving a conclusion from premisses that is epistemically independent of the truth of the conclusion but does not entail a counterfactual-supporting covering generalization. Their failure, however, at best justifies a presumption that the approach of Gerlofs and the similar approach of Bermejo-Luque are de facto equivalent to the position of the present article. 
8.4. Ennis: The present account of inference claims implies that all inference is general. If a conclusion follows from given premisses, then a parallel conclusion follows also from relevantly parallel premisses, even ones that are purely hypothetical. The generality of all inference undergirds the strategy sometimes called "refutation by logical analogy" (e.g. by Copi and Cohen (2001)), of challenging an inference by supplying a parallel argument with true (or otherwise acceptable) premisses and an untrue (or otherwise not acceptable) conclusion, perhaps prefixing one's challenge with the frame, "you might as well say that ..." On the broader truthtransmission conception of consequence that includes nonlogical consequences, a conclusion that follows from stated premisses does so in accordance with a counterfactualsupporting covering generalization that is non-trivially acceptable. If one restricts consequence to logical consequence or logical/semantic consequence, then one should look for such a generalization to add as an unexpressed premiss when one reconstructs the argument.

Proponents of the unexpressed premiss approach, however, sometimes object to the insistence that a gap-filling unexpressed premiss must be general by citing examples of what I will call "occasional arguments", which they claim have only a singular unexpressed premiss. Woods (2004, pp. 249-250) cites the argument:

(21) It's raining, so Eveline won't be driving to Calgary.

Although he does not describe the context of utterance of this apparently actual argument, it is a reasonable assumption that no counterfactual supporting covering generalization (such as 'Eveline doesn't drive when it's raining' or 'Unless it's an emergency, Eveline won't drive long distances when it's raining') is acceptable. The conclusion follows, we may suppose, in virtue of particulars of the occasion of utterance of the argument rather than in virtue of some covering generalization.

Robert Ennis claimed about a similar example that the gap-filling unexpressed premiss was the argument's associated singular conditional:

(22) ... when Michael Scriven and I were trying to find our way to Detroit airport in the car he rented, I said at one point, "The sign says 'Chicago' [to the right], so we should turn right there." (We were trying to get on I 94 going to the airport.) There was no generalization there (this is clear from the situation) 
and I would resist one. It was straight modus ponens, if anything. (e-mail communication, 2009 June 8)

Ennis later clarified in personal correspondence that he would not interpret the singular associated conditional that he took to be an unexpressed premiss of his argument as a material conditional. Aside from assuming that it licenses modus ponens, he did not ascribe truth-conditions to it. Much like Verheij, he envisaged it as an inferential conditional asserting that the conclusion of the stated argument follows from its premiss.

The inference in an occasional argument like those in examples (21) and (22) applies, on its face, only to the particular situation that is the occasion of its utterance. The word 'occasional' echoes Quine's use of the phrase 'occasion sentences' for sentences whose truth-value is partly a function of the occasion of their utterance (Quine, 1960). In the same way, the inferential goodness of occasional arguments is partly a function of the occasion of their utterance. But only partly, I shall argue. Once the relevant particular features of the occasion are specified, the conclusion follows if and only if some counterfactual-supporting covering generalization is nontrivially acceptable.

To understand an occasional argument, someone not present on the occasion of its utterance needs to know who uttered it, what particular individuals are being referred to by its constituent proper names and definite descriptions, and what background knowledge about those particular individuals is being taken for granted as shared between the arguer and the argument's addressees. Consider for example the argument cited by Ennis in example (22):

(23) The sign says 'Chicago' [to the right], so we should turn right there.

Ennis himself evidently found it necessary (or at least useful) to give part of the relevant background information in his e-mail communication: "Michael Scriven and I were trying to find our way to Detroit airport in the car he rented... We were trying to get on I 94 going to the airport." To complete the picture, we need to know that they were on I 96, having come across the Ambassador Bridge from Windsor. The sign on the right to which Ennis referred is located about half a mile before the exit to I 94. It reads: "I 94 West Chicago / I 94 East Port Huron". To fully understand the argument of example (23), we should add this additional information as unexpressed premisses mutually believed by both arguer and addressee: 
(24) We are trying to find our way to Detroit airport. We are trying to get on 194 going to the airport. We are on I 96, having come across the Ambassador Bridge from Windsor. The sign says 'Chicago' [to the right]. So we should turn right there.

Thus expanded with the information required for someone not present on the occasion to understand the argument, the argument fits very well the approach of the present article. The argument is an instance of the scheme:

(25) $x$ is trying to find $x$ 's way to Detroit airport. $x$ is trying to get on I 94 going to the airport. $x$ is on I 96, having come across the Ambassador Bridge from Windsor. The sign says 'Chicago' [to the right]. So $x$ should turn right there.

This argument scheme has no actual or counterfactual instances with true premisses and an untrue conclusion, even though it has an actual instance with true premisses (namely, the argument of example 24) and an actual instance with an untrue conclusion (for example, the instance in which the variable $x$ is replaced with the name of someone at the same spot on I 96 who intends to continue on that freeway past its intersection with I 94). Thus, the conclusion of the argument in example 24 follows from its premisses, since it is an instance of the scheme in example 25. The validity of that scheme corresponds to the truth of the covering generalization of the argument that anyone on I 96 who has come across the Ambassador Bridge from Windsor and is trying to get on I 94 going to the Detroit airport should turn right where the sign says "Chicago" to the right. And this covering generalization is non-trivially true, and supports counterfactual instances, as is required for the conclusion of the argument to follow from its premisses. It should be construed as temporally restricted to a specious present with indefinite boundaries, like the inference-licensing covering generalization of the Obama argument of example 6.

I suspect strongly that all occasional arguments will yield to a similar treatment. In other words, if the conclusion of an occasional argument intuitively follows from its premisses, it will follow from them in accordance with a non-trivially acceptable counterfactual-supporting covering generalization once the stated premisses are supplemented with the additional information about the occasion of the argument's utterance that is necessary for someone not present on that occasion to understand the argument. I invite readers to test this claim by 
working through an occasional argument that they themselves have experienced as arguer or addressee.

Occasional arguments exhibit the kernel of truth in the unexpressed premiss approach. Such arguments do need gapfilling supplementation by information about the topic of the argument (i.e. the individual person or thing referred to in both premisses and conclusion), information that is taken for granted as known (or at least believed) by both arguer and addressees. But this supplementation usually does not produce an argument that is formally valid. Rather, it produces an argument with an inference-claim that is at least arguably correct, in the sense that some non-trivially acceptable counterfactual-supporting covering generalization licenses the drawing of the conclusion from the supplemented premiss set. In general, the function of such context-available information is to narrow the scope of an obvious covering generalization so that it is a plausible candidate for being non-trivially true and supporting counterexamples. In the argument of example 23 about turning right where the sign says "Chicago", for example, the additional premisses narrow the scope of the generalization that one should turn right where the sign says "Chicago" from all persons to all persons in a specious present who are travelling from the Ambassador Bridge on I 96 and trying to get on I 94 going to Detroit airport

\section{Summary}

Contemporary logicians generally construe consequence as formally necessary truth-preservation: a purely formal feature rules out that the implicans is true while the implicatum is untrue. Two objections can be raised to this conception. First, it counts something as a consequence simply because a purely formal feature rules out that the implicans is true or simply because a purely formal feature rules out that the implicatum is untrue. Second, it rejects something as a consequence when a general but not purely formal feature rules out a true implicans and untrue implicatum. An alternative truth-transmission conception holds that a consequence relation obtains when and only when a general feature rules out that the implicans is true while the implicatum is untrue, even though it does not rule out that the implicans is true and does not rule out that the implicatum is untrue. Both conceptions can be given substitutional, model-theoretic or schematic articulations. However, each of these three articulations of the truthtransmission conception has counter-examples where the conclusion of an argument obviously does not follow from its 
premisses even though the argument satisfies the articulation in question. The remedy is to abandon the substitutional and model-theoretic articulations and to modify the schematic articulation so as to require that it holds in virtue of a counterfactual-supporting covering generalization. This modification introduces an awkward asymmetry into the evaluation of arguments: covering generalizations that hold merely of actual cases have to be treated as unexpressed premisses rather than as principles licensing an inference. The suspicion that the asymmetry indicates something wrong-headed about the whole approach can be countered by noting that people rarely argue for conclusions that follow only in accordance with a covering generalization that if true would not support counterfactual instances; an explanation of their rarity is that to argue in this way is to beg the question at issue.

The modified truth-transmission conception of consequence can be elaborated and expanded in four ways: by recognizing the legitimacy of restricting the range of the variables in an argument's schema, by generalizing from truth to acceptability to cover deontic conclusions, by allowing for conclusions that are not assertives, and by allowing for rebuttable inferences. On the elaborated and expanded account, a conclusion follows from given premisses if and only if an acceptable counterfactual-supporting covering generalization of the argument rules out, either definitively or with some modal qualification, simultaneous acceptability of the premisses and non-acceptability of the conclusion, even though it does not rule out acceptability of the premisses and does not require acceptability of the conclusion independently of the premisses.

This elaborated and expanded account is rather complex. A sceptic might find more attractive the simpler view already held by ancient logicians that the inference claim of an argument is just its associated conditional, i.e. the singular conditional whose antecedent is the conjunction of the argument's premisses and whose consequent is the argument's conclusion In response to such a sceptic, we may grant that a singular indicative conditional in one of its senses signifies that its consequent follows from its antecedent, but take the expanded acceptabilitytransmission account of the consequence relation to be an account of the truth-conditions of a singular indicative conditional in that sense. The alternative view that the inference claim of an argument is singular rather than general is either subject to objections or equivalent to the expanded acceptability-transmission account. The view that the unexpressed premiss of a formally invalid argument is at least sometimes the argument's associated conditional is likewise either subject to objections or equivalent to the present account. 


\section{Appendix}

The universally generalized material conditional associated with the schema 'People who are $F$ are very poor soldiers, so the Iraqi soldiers are not $F^{\prime}$ is logically equivalent to the statement that the Iraqi soldiers are not very poor soldiers.

Proof: ( $L$ to $R$ ) Suppose that, for any $F$, if people who are $F$ are very poor soldiers, then the Iraqi soldiers are not $F$. Then in particular, by universal instantiation, if people who are identical with the Iraqi soldiers are very poor soldiers, then the Iraqi soldiers are not identical with the Iraqi soldiers. But, by the meaning of identity, the Iraqi soldiers are identical with the Iraqi soldiers. Hence, by double negation and modus tollendo tollens, people who are identical with the Iraqi soldiers are not very poor soldiers. In other words, the Iraqi soldiers are not very poor soldiers.

$(R$ to $L)$ Suppose that the Iraqi soldiers are not very poor soldiers. Now suppose, for conditional proof, that for an arbitrarily chosen property $F$, people who are $F$ are very poor soldiers. Suppose, for reductio, that the Iraqi soldiers are $F$. Since they are people, they are people who are $F$, and thus are very poor soldiers, contrary to our original supposition. Hence, by reductio ad absurdum, the Iraqi soldiers are not $F$. Hence, by conditional proof, if people who are $F$ are very poor soldiers, then the Iraqi soldiers are not $F$. Hence, since we have discharged all assumptions about $F$, by universal generalization, for any $F$, if people who are $F$ are very poor soldiers, then the Iraqi soldiers are not $F$. QED

The proof uses only rules of inference that conform to the truth-transmission sense of consequence. It can be imitated for any argument in which an additional singular premiss would make the argument formally valid. Any singular statement is thus equivalent to a second-order universal generalization, which if it supports counterfactual instances can license inferences.

Acknowledgements: I wish to express particular thanks to Lilian Bermejo-Luque, Robert Ennis, James Freeman and Robert Pinto for sustained correspondence on issues discussed in this article. I thank as well for helpful comments on earlier versions of this article George Boger, Ralph Johnson, Ernest Lepore, Harvey Siegel and Mark Weinstein. They will not necessarily agree with the result, the responsibility for which is mine. 
The present article is to appear in slightly different form in the proceedings of a colloquium entitled "Inside arguments: logic vs. argumentation theory", held at the University of Coimbra in Portugal from March 24 through 26, 2011. I am grateful to the editors of the conference proceedings and of Informal Logic for permitting the dual publication.

\section{References}

Aristotle (1984). Rhetoric. In: J. Barnes (Ed.), The Complete Works of Aristotle, vol. 2 (pp. 2152-2269), Princeton: Princeton University Press.

Arregui, A. (2009). On similarity in counter-factuals. Lingustics and Philosophy 32, 245-278.

Barnes, J. (2007). Truth, etc. Six Lectures on Ancient Logic. Oxford: Clarendon Press.

Bermejo-Luque, L. (2006). Toulmin's model of argument and the question of relativism. In: D. Hitchcock and B. Verheij (Eds.), Arguing on the Toulmin Model: New Essays in Argument Analysis and Evaluation (pp. 71-85, Ch. 6), Dordrecht: Springer.

Bermejo-Luque, L. (2011a). Giving Reasons: A Linguistic Approach to Argumentation Theory. Argumentation Library, Vol. 20. Dordrecht, The Netherlands: Springer.

Bermejo-Luque, L. (2011b). Exchanging reasons: responses to critics. Theoria 72, 224-238.

Carroll, J.W. (2011) Laws of nature. In: E.N. Zalta (Ed.), The Stanford Encyclopedia of Philosophy (Spring 2011 Edition), $\mathrm{URL}=$

$<$ http://plato.stanford.edu/archives/spr2011/entries/laws-ofnature $/>$.

Copi, I.M. and C. Cohen. (2001). Introduction to Logic, 11th edition. Upper Saddle River, NJ: Prentice-Hall.

Davies, E.C. (1979). On the Semantics of Syntax. Mood and Condition in English. London: Croom Helm.

Diogenes Laertius (2005/c. 235). Lives of Eminent Philosophers, Books VI-X, tr. R.D. Hicks. Loeb Classical Library 185. Cambridge, MA: Harvard University Press.

Eemeren, F.H. van and R. Grootendorst (1992). Argumentation, Communication, and Fallacies: A Pragma-Dialectical Perspective. Hillsdale, NJ: Lawrence Erlbaum Associates.

Etchemendy, J. (1990). The Concept of Logical Consequence. Cambridge, MA: Harvard University Press.

Ennis, R.H. (1982). Identifying implicit assumptions. Synthese $51,61-86$. 
Forbes, G. (1994). Modern Logic. New York: Oxford University Press.

Freeman, J.B. (2011a). Argument Structure: Representation and Theory. Dordrecht, The Netherlands: Springer.

Freeman, J.B. (2011b). The logical dimension of argumentation and its semantic appraisal in Bermejo-Luque's Giving Reasons. Theoria 72, 189-198.

Gerlofs, J.M. (2009). The Use of Conditionals in Argumentation. Diss., University of Amsterdam.

Gerlofs, J.M. (2011). Hidden premises, hidden treasures? In: F.H. van Eemeren, B. Garssen, D.M. Godden and G.R. Mitchell (Eds.), Proceedings of the Seventh Conference of the International Society for the Study of Argumentation. Chapter 52, pp. 577-586. CD-ROM. Amsterdam: Sic Sat.

Grice, Paul (1989). Studies in the Way of Words. Cambridge, MA: Harvard University Press.

Hitchcock, D. (1985). Enthymematic arguments. Informal Logic 7(2 and 3), 83-97.

Hitchcock, D. (1992). Relevance. Argumentation 6, 251-270.

Hitchcock, D. (1998). Does the traditional treatment of enthymemes rest on a mistake? Argumentation 12, 15-37.

Hitchcock, D. (2002) Sampling scholarly arguments: a test of a theory of good inference In: H.V. Hansen, C.W. Tindale, J.A. Blair, R.H. Johnson and R.C. Pinto (Eds.), Argumentation and Its Applications, CD-ROM (pp. 1-20, with Appendix, pp. 1-58), Windsor, ON: OSSA.

Hitchcock, D. (2006). Informal logic and the concept of argument. In: D. Jacquette (Ed.), Philosophy of Logic, volume 5 of D.M. Gabbay, P. Thagard and J. Woods (Eds.), Handbook of the Philosophy of Science (pp. 101-129), Amsterdam: North Holland.

Hitchcock, D. (2009). Non-logical consequence. Studies in Logic, Grammar and Rhetoric 16(29), 137-158.

Hitchcock, D. (2010a). The culture of spoken arguments. In: J. Ritola (Ed.), Argument Cultures: Proceedings of OSSA 09, CD-ROM (pp. 1-19, with Appendix, pp. 1-66), Windsor, ON: OSSA.

Hitchcock, D. (2010b). The generation of argumentation schemes. In: C. Reed and C.W. Tindale (Eds.), Dialectics, Dialogue and Argumentation: An Examination of Douglas Walton's Theories of Reasoning and Argument, Chapter 12 (pp. 157-166), London: College Publications.

Hurley, P.J. (2006). A Concise Introduction to Logic, 9th edition. Belmont, CA: Wadsworth/Thomson.

Jeffrey, R. (2006). Formal Logic: Its Scope and Limits, 4th edition, edited, with a new supplement, by J.P. Burgess. Indianapolis: Hackett. 
Johnson, R.H. and J.A. Blair (1993). Logical Self-Defense, 3rd edition. Toronto: McGraw-Hill Ryerson.

Kneale, W. and M. Kneale (1962). The Development of Logic. Oxford: Clarendon Press.

Lewis, C.I. (1912). Implication and the algebra of logic. Mind 21, 522-531.

Lewis, D.K. (1973). Counterfactuals. Cambridge, MA: Harvard University Press.

Pearl, J. (2000). Causality: Models, Reasoning, and Inference. Cambridge: Cambridge University Press.

Pinto, R.C. (2011). The account of warrants in Bermejo-Luque's Giving Reasons. Theoria 72, 207-216.

Quine, W.V.O. (1960). Word and Object. Cambridge, MA: MIT Press.

Quine, W.V.O. (1972). Methods of Logic, 3rd edition. New York: Holt, Rinehart and Winston.

Salmon, W.C. (1963). Logic. Englewood Cliffs, NJ: PrenticeHall.

Searle, J. (1979). Expression and Meaning: Studies in the Theory of Speech Acts. Cambridge: Cambridge University Press.

Sextus Empiricus (1997/c. 180). Against the Logicians, tr. R.G. Bury. Loeb Classical Library 291. Cambridge, MA: Harvard University Press.

Sher, G.Y. (1996). Did Tarski commit "Tarski's fallacy"? Journal of Symbolic Logic 61, 653-686.

Tarski, A. (2002/1936). On the concept of following logically. Tr. M. Stroi ska and D. Hitchcock. History and Philosophy of Logic 23, 155-196.

Tennant, N. (1979). Entailment and proofs. Proceedings of the Aristotelian Society 79, 167-189.

Tennant, N. (1980). A proof-theoretic approach to entailment. Journal of Philosophical Logic 9, 185-209.

Tennant, N. (1984). Perfect validity, entailment and paraconsistency. Studia Logica 43, 179-198.

Toulmin, S.E. (1958). The Uses of Argument. Cambridge: Cambridge University Press.

Verheij, B. (2006). Evaluating arguments based on Toulmin's scheme. In: D. Hitchcock and B. Verheij (Eds.), Arguing on the Toulmin Model: New Essays in Argument Analysis and Evaluation (pp. 181-202, Ch. 12), Dordrecht, The Netherlands: Springer, 181-202.

Verheij, B. (2010). Argumentation and rules with exceptions. In: P. Baroni, F. Cerutti, M. Giacomin \& G.R. Simari (Eds.), Computational Models of Argument. Proceedings of COMMA 2010. Frontiers in Artificial Intelligence and Applications 216. Amsterdam: IOS Press, 455-462. 
Inference Claims 229

Whitehead, A.N. and B. Russell (1910-1913). Principia Mathematica, 3 vols. Cambridge: Cambridge University Press.

Woods, J. (2004). The Death of Argument: Fallacies in AgentBased Reasoning. Applied Logic Series, volume 32. Dordrecht: Kluwer. 